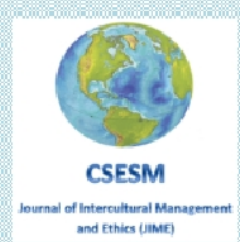

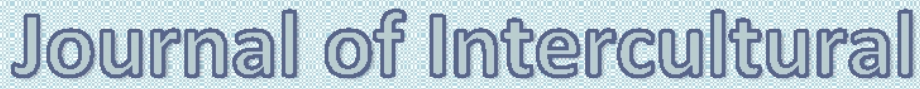

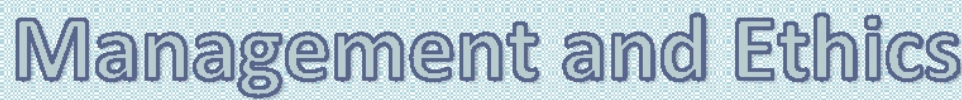

\author{
IOME
}

ISSN 2601 - 5749, ISSN-L 2601 - 5749

\section{published by zy \\ Center for Socio-Economic Studies and Multiculturalism \\ lasi, Romania \\ Waw csesmorg}




\section{Special Editor}

\section{Professor Beatrice Gabriela Ioan, PhD, MD}

Grigore T.Popa University of Medicine and Pharmacy of Iasi, Romania

E-mail: ioanbml@yahoo.com

\section{TABLE OF CONTENT}

Editorial

Beatrice Gabriela Ioan

Global Pandemics: Considerations of Public Health, Human Rights, and Bioethics

SanaLoue

Reactions of Bioethics to the Covid-19 Pandemic 19

Elena Toader, Luiza Palamaru, Tudor Stefan Rotaru, Oana Hrisca Eva

Implications of Cognitive-Behavioural Therapy in Changing Illness Representations .27

Ancuța Elena Păduraru, Camelia Soponaru

Healthcare Workers - Heroes and Villains in Covid-19 Pandemic. The Ethical

Communication

Ioana Silistraru

Ethical Dilemmas in the Therapeutic Management of Patients with Sars-Cov-2 Infection .. 45 Claudia Elena Pleşca, Ioana Hunea, Maria Obreja, Oana Stămăteanu, Delia Luchian, Irina Dima, Larisa Miftode, Tudorița Gabriela Părângă, Egidia Miftode, Simona Apostu, Camelia Bucur, Daniela Leca

Covid - 19 through the Window of Age 55

Elena Toader, Daniela Damir, Tudor Winzinger

Ethical Aspects of "Do Not Resuscitate" Orders in the Context of the Covid-19 Pandemic 61 Iulius Connor Gramma, Gema Bacoanu, Beatrice Gabriela Ioan

Ethics of the Human-Animal Relationship in the Covid-19 Pandemic .67

Cristin Coman, Diana Ancuta 


\title{
HEALTHCARE WORKERS - HEROES AND VILLAINS IN COVID-19 PANDEMIC. THE ETHICAL COMMUNICATION
}

\author{
Ioana Silistraru \\ "Lucian Blaga" University of Sibiu, Romania \\ e-mail: ioana.silistraru@icloud.com
}

\begin{abstract}
Periods of social and health crises require more than ever more attention to professional ethics, both for health practitioners and communicators. Beyond each profession's specific ethics, today, the fields are interdependent, with a transfer between the two professions. As a consequence of the transfer, ethical questions arise, some behaviours and statements are placed at their limit in both cases. This interpenetration of roles, assumed in a professional or private capacity, is augmented in social networks, permissive for a wide range of narrative manifestations. The article takes into account the narratives agglutinated around the concepts that have polarized Romania's public discourse since the official declaration of the pandemic, of "doctor-hero" and "doctor-villain." The narratives identified in the social networks are inventoried from the perspective of the situation on this scale of the social emotion, the information it reveals to the public, and then analysed from the professional, ethical angle. The findings set the ground for preliminary analysis, without claiming to be exhaustive, of how the medical profession is perceived ethically in the pandemic context. A complex approach to the topic can suggest answers to questions such as - How much does the doctor's social media activity contribute to informing and educating the public? Is this activity desirable or even recommended for medical staff? Is it possible to delimit the role of a physician when expressing opinions in public space? The effect of this effervescence in communication, corroborated with the total democratization of the digital space, with non-discriminatory access for any communicator, is complex. The social network has the potential of a virtual bullying space, artificially fed. In this context, we could further explore by coding (positive-negative) how the pandemic narrative defines and redefines the medical profession and its most visible exponent - the doctor, and its public manifestation simultaneously positions him as a "hero" and "villain".
\end{abstract}

Keywords: communication, ethics, healthcare worker, COVID-19

\section{Healthcare communication - a $360^{0}$ concept}

COVID-19 pandemic has been profoundly redefining communication streamline, both from a personal and professional perspective. Individual and groups' lifestyle has been impacted, both short-term and long-term, as the long-term impact has still to be investigated in time (Chew, Wei, Vasoo, \& Sim, 2020; Kar, Yasir Arafat, Kabir, Sharma, \& Saxena, 2020).

Communication as a social impact activity should consider how trust, accuracy, and impact on the general public's perception (Huntington \& Kuhn, 2003) should be considered. While the COVID-19 crisis unfolds in Romanian society, healthcare voices through public communication touchpoints have become both an ethical issue and an opportunity, managed responsibly.

One should look at the communication as a whole, emerged from a previously established professional reputation - healthcare providers are still associated with the patriarchal style of communication, regardless of a very active 
While analysing communication that emerged in the healthcare environment (communication perpetuated in the public sphere by physicians, nurses, managers, and other healthcare professionals) around COVID-19 topics, we propose a three-sided approach to emphasize the complexity and sensitivity of crisis communication. We capture the social, psychological, and communication impact of emerged narratives to underline the general public's responsibility in healthcare communication activities. Should healthcare providers be especially active in social media or audio-visual media is one debatable issue (McCartney, 2012), while the author agrees that professionalism and social media presence can be an uneasy mix. In 2011 The American Medical Association suggested that doctors should separate professional and personal content online and "must recognize that actions online and content posted may negatively affect their reputations among patients and colleagues, may have consequences for their medical careers (particularly for physicians-in-training and medical students), and can undermine public trust in the medical profession." (AMA, 2018)

"Participating in social networking and other similar opportunities can support physicians' expression, enable individual physicians to have a professional presence online, foster collegiality and camaraderie within the profession, provide opportunities to disseminate public health messages and other health communication widely," notes the preamble to Opinion, 2.3.2, "Professionalism in the Use of Social Media." (AMA, 2018)

"Social networks, blogs and other forms of communication online also create new challenges to the patient-physician relationship," the Code of Medical Ethics says (AMA, 2001).

While looking at COVID-19 communication revolving around the healthcare professionals, we determine the position the physician holds within society; therefore, we can analyze his/her communication from a sociological perspective as an active, preeminent, and trustworthy member of our society. While going through an unprecedented health crisis, we must note that regardless of fair utilization of modern concepts of healthcare as Centred Patient Care (CPC) or Shared Decision Making (SDM), our society is still connected to a patriarchal view on physicians' authority (Silistraru, 2020)

\section{Social media networking sites (SNS)}

Social networking sites have an increased influence (Maughan \& Economou, 2015) on patients and general public perception of healthcare, especially during the Covid-19 crisis, up to a clinical dilemma to what extent healthcare practitioners should extensively communicate in social media. The American Medical Association provides healthcare professionals with guidelines to respond to the communication needs of physicians (AMA, 2001), which states concerning a communication that 'A physician shall recognize a responsibility to participate in activities contributing to the improvement of the community and the betterment of public health', among other principles of medical ethics.

\section{Professional responsibility in narrative polarisation}

While posting on social media, commenting on unfolding crises, participating in polarised conversations or media debates, it has been noted that healthcare professionals contribute to the abovementioned polarisation of narratives. As we add to the conversational landscape medical knowledge and opinion, outside the clinical context, physicians should be aware of the risk that behaviour entangles (McCartney, 2012). While exposing the professional responsibility, one should analyse the psychological mechanism behind the mass-media polarisation of COVID-19 narratives. 


\section{Why we read social media so differently?}

While being in a fast-moving forward sanitary crisis, augmented by dramatic media accounts that feed the public fear and anxiety, public and specialized communication should be carefully prepared and disseminated responsibly. The new forms of sociality on the Internet (Fainzang, 2018, p. 154) underline individuals' tendency to develop social connections and groups based on their beliefs. Literature states that diverse forms of sociality are based on the experience of illness or medicine or a personal doctrine, as an advocate or opponent. The public finds himself either in a therapeutic quest, either looking for social recognition or asserting competence (Fainzang, 2018, p. 155). The sanitary crisis has a significant impact on the mental health of the general public and the healthcare professionals who are strained into the crisis in delivering immediate medical care and situational response (Chew et al., 2020). As the social landscape and social behaviour are subject to change, the toll on psychological wellbeing has been exposed, primarily through Internet-mediated social media illness accounts (Barello, Palamenghi, \& Graffigna, 2020; Hartzband, 2020; Restauri \& Sheridan, 2020).

The role played by emotions in wiring our response to health anxiety has been recognized and conceptualized within the new approach to the inferential brain's emotions and cognitive designs. We see a building up a connection between the worrisome and frustrated socially deprived individual in consecutive lockdowns during the COVID-19 pandemic and the appetite for Internet-mediated polarised narratives. We see a rising incidence of depression and anxiety among very different populations during consecutive lockdowns internationally, and the literature states the public health threat derived from social isolation (Armitage \& Nellums, 2020; Magill, Siegel, \& Pike, 2020; Ni, Leung, \& Leung, 2020; Parolin, 2020; Williams et al., 2020). With concerns rising as of socially isolated individuals' mental health, coping mechanisms are investigated to identify adaptative cognitive schemes and behaviours utilized by different populations. As we still navigate the pandemic, although mental health studies have been coming out gradually, there is still a need for time to pass to replicate the findings (Kar et al., 2020).

The literature so far identified a series of coping mechanisms that generate adaptive behaviour when confronted with isolation and subsequent social and personal limitations. Future research on coping response is nevertheless encouraged to replicate current findings on adaptive and maladaptive coping strategies while confronted with mental health issues (Volk, Brazil, Franklin-Luther, Dane, \& Vaillancourt, 2021).

\section{The narrative paradigm of "Hero and villain".}

Since the beginning of the pandemic with polarised, antagonized narratives, the Romanian narrative landscape has been populated in recent months, including healthcare professionals. One recurrent theme has been the one describing doctors and nurses, members of "first-line-healthcare workers," frontline healthcare workers", a military-related metaphor, and a parallel to some of the most risk-exposed "soldiers" of the pandemic, as the "heroes/saints" and "villains". The discourse polarisation has emerged from the social and sanitary reality -frontline healthcare workers have been exposed to COVID-19 infections, with a higher risk of reporting a positive test than other healthcare professional categories (Nguyen et al., 2020). Public and SNS discourse has been taking into account the reality of frontline workers and popularized the theme of "heroes" and "villains" (whereas iatrogenic stories have emerged in uncontrolled and unmoderated narratives through social media touchpoint - forums, discussion groups, and personal stories). While internationally frontline healthcare workers have been praised and acclaimed, Romania has reported one significant transfer of the hero narratives into outdoor advertising and social media posts, portraying the doctors as saints. The short-lived advertising campaign served as a pretext to fuel more 
polarised narratives. Interestingly enough, some healthcare workers themselves have rejected the 'hero narrative' close to being offended by such a creative approach. Nevertheless, signs of gratitude and professional acknowledgment have occurred internationally, as a spontaneous encouragement of nurses and doctors in COVID-19 medical facilities in Italy (AP, 2020), USA (TIME, 2020) or UK (BBC, 2020).

Medical practice has been significantly disrupted by the pandemic regulations and patients' worrisome behavior. Discipline and compliance have been reported to be an issue with American patients who less frequently addressed their physicians for chronic illnesses and overused available medication improperly (Dallas CRPS RSD Lawsuit News, 2020).

Romanian media has also reported a fluctuance in chronic illness patients' access to treatment and care (Foarfecă, 2021). Moreover, a decrease in medical procedures performed during the past year. Most of the "negative hero" narratives identified on SNS present personal illness accounts from patients with different pathologies. Romanian Health Observatory report accounts for a $80 \%$ decrease in the number of admittances for HIV patients, $67 \%$ decrease in admittance of diabetes patients, $57 \%$ fewer multiple sclerosis patients admitted in Romanian hospitals, $50 \%$ for patients with tuberculosis and $46 \%$ fewer admittances for cancer patients during 2020. In April 2020 in Romania were admitted 70\% fewer patients compared to April 2019, according to data published by Romanian Health Observatory (ORS, 2020). With the democratization of public communication, personal stories, sufferance, and illness accounts of patients are most likely to be found in open discussions on social media, producing a high-level of social emotions and, subsequently, praising or incriminating narratives of the Romanian flawed healthcare system.

\section{Discussions}

Paying attention to populations' narratives related to healthcare might indicate how the medical profession's perception is shaping up into the future. While the pandemic situation and social limitations are still unfolding, with an on-going vaccination campaign and efforts to limit the effects of COVID-19 infections, especially within the vulnerable populations, trust is of crucial importance. Trust and confidence patients have in the medical profession and healthcare providers are valuable assets to be nurtured within society (Shale, 2012). Although changes have been made in patient-doctor relationships and communication for the past years in one direction of modern concepts of Patient-Centered Care (PCC) and Shared Decision Making (SDM), accumulated momentum might be threatened during COVID- 19 pandemic, with a significant effect in the future therapeutical relationship. As trust and confidence set-up a modern healthcare relationship, ensuring treatment compliance and reasonable medical, psychological and social costs of healthcare, this relationship must be nurtured even in difficult times.

\section{References}

AMA. (2001). AMA Code of Medical Ethics. American Medical Association (AMA), (June 2001), 17-18.

AMA. (2018). Social media guidance for physicians taps timeless principles. Retrieved April 13, 2021, from https://www.ama-assn.org/delivering-care/ethics/social-mediaguidance-physicians-taps-timeless-principles

AP. (2020). AP Photos: Italy's front-line medical heroes, 8 months later. Retrieved from https://apnews.com/article/pandemics-health-italy-coronavirus-pandemic-only-on-ap-

Armitage, R., \& Nellums, L. B. (2020). COVID-19 and the consequences of isolating the elderly. The Lancet Public Health, 5(5), e256. https://doi.org/10.1016/S24682667(20)30061-X

Barello, S., Palamenghi, L., \& Graffigna, G. (2020). Burnout and somatic symptoms among 
frontline healthcare professionals at the peak of the Italian COVID-19 pandemic. Psychiatry Research, 290(May). https://doi.org/10.1016/j.psychres.2020.113129

BBC. (2020). Coronavirus: Portraits of NHS frontline "heroes.". Retrieved from https://www.bbc.com/news/uk-england-york-north-yorkshire

Chew, Q. H., Wei, K. C., Vasoo, S., \& Sim, K. (2020). Psychological and Coping Responses of Health Care Workers Toward Emerging Infectious Disease Outbreaks: A Rapid Review and Practical Implications for the COVID-19 Pandemic. The Journal of Clinical Psychiatry, 81(6), 350-356. https://doi.org/10.4088/JCP.20r13450

Dallas CRPS RSD Lawsuit News. (2020). Are Bad Doctors, Medical Errors Being Ignored Due to COVID-19?.Retrieved from https://dallas.legalexaminer.com/health/are-baddoctors-medical-errors-being-ignored-due-to-covid-19

Fainzang, S. (2018). New forms of sociality on the Internet. In Emerging Socialities in 21st Century Health Care (pp. 151-162). https://doi.org/10.2307/j.ctv5npjsq.14

Foarfecă, E. (2021). Epidemia nu afectează doar bolnavii de Covid-19. Sute de mii de pacienţi cronici au nevoie de îngrijiri medicale. www.mediafax.ro/social/epidemia-nuafecteaza-doar-bolnavii-de-covid-19-sute-de-mii-de-pacienti-cronici-au-nevoie-deingrijiri-medicale

Hartzband, P. (2020). Physician Burnout, Interrupted. New England Journal of Medicine, 12. https://doi.org/DOI: 10.1056/NEJMp2009027

Huntington, B., \& Kuhn, N. (2003). Communication gaffes : a root cause of malpractice claims. Bayl University Medical Centre Proceedings, 16(2), 157-161.

Kar, S. K., Yasir Arafat, S. M., Kabir, R., Sharma, P., \& Saxena, S. K. (2020). Coping with Mental Health Challenges During COVID-19. In S. K. Saxena (Ed.), Coronavirus Disease 2019 (COVID-19): Epidemiology, Pathogenesis, Diagnosis, and Therapeutics (pp. 199-213). Singapore: Springer Singapore. https://doi.org/10.1007/978-981-15-4814-7_16

Magill, E. B., Siegel, Z. B., \& Pike, K. M. (2020). The Mental Health of Frontline Healthcare Providers During Pandemics: A Rapid Review of the Literature. Psychiatric Services, (in press), 1-30. https://doi.org/10.1176/appi.ps.202000274

Maughan, D. L., \& Economou, A. (2015). Social networking sites: A clinical dilemma? Journal of Medical Ethics, 41(2), 203-205. https://doi.org/10.1136/medethics-2013101341

McCartney, M. (2012). How much of a social media profile can doctors have? BMJ (Online), 344(7841), 1-3. https://doi.org/10.1136/bmj.e440

Nguyen, L. H., Drew, D. A., Graham, M. S., Joshi, A. D., Guo, C. G., Ma, W., ... Zhang, F. (2020). Risk of COVID-19 among front-line health-care workers and the general community: a prospective cohort study. The Lancet Public Health, 5(9), e475-e483. https://doi.org/10.1016/S2468-2667(20)30164-X

Ni, M. Y., Leung, C. M., \& Leung, G. M. (2020). The epidemiology of population mental wellbeing in China. The Lancet Public Health, 5(12), e631-e632. https://doi.org/10.1016/S2468-2667(20)30265-6

ORS. (2020). IMPACTUL PANDEMIEI COVID-19 asupra accesului bolnavilor cronici la servicii medicale - Focus pe TBC, HIV, oncologie, diabet.

Parolin, Z. (2020). Unemployment and child health during COVID-19 in the USA. The Lancet Public Health, 5(10), e521-e522. https://doi.org/10.1016/S24682667(20)30207-3

Restauri, N., \& Sheridan, A. D. (2020). Burnout and Posttraumatic Stress Disorder in the Coronavirus Disease 2019 (COVID-19) Pandemic: Intersection, Impact, and Interventions. Journal of the American College of Radiology, 17(7), 921-926. https://doi.org/10.1016/j.jacr.2020.05.021 
Shale, S. (2012). Moral Leadership in Medicine - Building Ethical Healthcare Organizations. Cambdridge University Press. https://doi.org/10.1108/lhs.2012.21125caa.008

Silistraru, I. (2020). Narațiunea medicală în românia în domeniul bolilor cardiovasculare.

TIME. (2020). Meet the Heroes of the Front Lines. https://time.com/collection/coronavirusheroes/

Volk, A. A., Brazil, K. J., Franklin-Luther, P., Dane, A. V, \& Vaillancourt, T. (2021). The influence of demographics and personality on COVID-19 coping in young adults. Personality and Individual Differences, 168, 110398. https://doi.org/https://doi.org/10.1016/j.paid.2020.110398

Williams, R., Jenkins, D. A., Ashcroft, D. M., Brown, B., Campbell, S., Carr, M. J., ... Peek, N. (2020). Diagnosis of physical and mental health conditions in primary care during the COVID-19 pandemic: a retrospective cohort study. The Lancet Public Health, 5(10), e543-e550. https://doi.org/10.1016/S2468-2667(20)30201-2 